\title{
Biography: Kamal Mahawar
}

\author{
Kamal Mahawar ${ }^{1}$
}

Published online: 20 September 2018

(C) Springer Science+Business Media, LLC, part of Springer Nature 2018

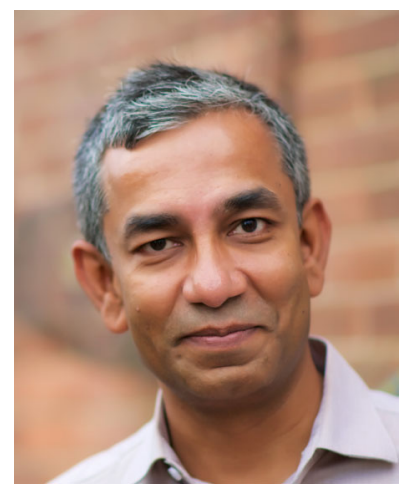

Mr. Kamal Mahawar is a Consultant General and Bariatric Surgeon at Sunderland Royal Hospital, in North East of England. He takes a significant interest in research in bariatric surgery and regularly writes on related topics. He has coauthored over 100 peer-reviewed articles and multiple book chapters. He was recently awarded an honorary professorship at Shri Aurobindo Medical College and Postgraduate Institute, Indore (MP), India. Mr. Mahawar is also affiliated with Newcastle University as an Associate Clinical Lecturer and Sunderland University as a Visiting Research Fellow. He served as an honorary clinical tutor at the University of Edinburgh from 2014 to 2016. Mr. Mahawar has authored many highly cited systematic reviews in areas of controversy in bariatric surgery with an overarching aim to simplify bariatric surgery and improve its safety.

Mr. Mahawar grew up in Kolkata, India, and obtained his medical degree from the Kolkata Medical College in 1996 with multiple honours and medals. He was ranked first in the college in the final MBBS examination of the University and received the BC Roy Award from Mr. I K Gujral, then

Kamal Mahawar

kmahawar@gmail.com

1 Bariatric Unit, Department of Surgery, Sunderland Royal Hospital, Sunderland SR4 7TP, UK
Prime Minister of India. He then went on to obtain his MS (Master of Surgery) in General Surgery from the Prestigious PGIMER in Chandigarh in 2000 before emigrating to the UK. In the UK, Kamal obtained an MSc with distinction from the Liverpool University and obtained further surgical training in the Northern Deanery. He ultimately obtained the Fellowship of the Royal College of Surgeons of Edinburgh (FRCSEd) in 2010.

Kamal is also a non-fiction writer. His book "The Ethical Doctor" written on the current state of Indian healthcare and published by Harper Collins in 2016 received widespread media coverage in India and abroad and may have proved to be a catalyst for an enhanced focus on healthcare from the media, the civil service, and the policymakers in India. His second book is currently under publication.

Mr. Mahawar is widely recognised within bariatric circles for his contributions to the understanding and development of One Anastomosis Gastric Bypass. He contributed a series of articles, finally culminating into the recent publication of the first consensus paper on this rapidly growing bariatric procedure. Mr. Mahawar has been an invited faculty and guest speaker at many national and international conferences. In addition, he serves on a number of important committees of prestigious societies including IFSO, BOMSS, ASMBS, ASGBI, and BMA. $\mathrm{He}$ is on the editorial board of "Obesity Surgery" and is also its first Social Media Editor. He is also an Associate Editor of "Clinical Obesity." He regularly mentors healthcare professionals from around the world on academic and research matters. He is an enthusiastic surgical trainer and a recognised UK mentor for One Anastomosis Gastric Bypass. Kamal has set up multiple email chat groups with hundreds of users and social media networking groups with thousands of members to facilitate interactions among healthcare professionals working in the field of bariatric surgery.

Mr. Kamal Mahawar lives in Newcastle upon Tyne with his wife Shalini, a software engineer, and his son Kush. He can be freely contacted at kmahawar@gmail.com. 